\title{
Specialist Physicians in Geriatrics- \\ Report of the Canadian Geriatrics Society \\ Physician Resource Work Group*
}

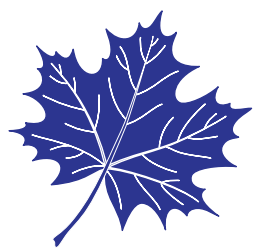

David B. Hogan, MD, FRCPC ${ }^{1}$, Michael Borrie, MD, FRCPC ${ }^{2}$, Jenny F.S. Basran, MD, FRCPC ${ }^{3}$, A. Maria Chung, MD, FRCPC ${ }^{4}$, Pamela G. Jarrett, MD, FRCPC ${ }^{5}$, José A. Morais, MD, FRCPC ${ }^{6}$, Eileen Peters, MD ${ }^{7}$, Kenneth J. Rockwood, MD, FRCPC ${ }^{5}$, Philip D. St. John, MD, MPH, FRCPC ${ }^{8}$, Anne L. Sclater, MD, FRCPC ${ }^{9}$, Timothy Stultz, MD ${ }^{10}$, Sarah Woolmore-Goodwin, BA (SPEC HONS), MSc ${ }^{2}$

${ }^{1}$ Division of Geriatric Medicine, University of Calgary, Calgary, AB; ${ }^{2}$ Division of Geriatric Medicine, University of Western Ontario, London, ON; ${ }^{3}$ Division of Geriatric Medicine, University of Saskatchewan, Saskatoon, SK; ${ }^{4}$ Division of Geriatric Medicine, University of British Columbia, Vancouver, BC; ${ }^{5}$ Division of Geriatric Medicine, Dalhousie University, Halifax, NS; ${ }^{6}$ Division of Geriatric Medicine, McGill University, Montreal, PQ; ${ }^{7}$ Frame Lake Community Health Clinic, Yellowknife, Northwest Territories; ${ }^{8}$ Division of Geriatric Medicine, University of Manitoba, Winnipeg, MB; ${ }^{9}$ Department of Medicine, Memorial University, St. John's, NL; ${ }^{10}$ Provincial Geriatric Program, Health PEI, Summerside, PEI

DOI:http://dx.doi.org/10.5770/cgj.15.41

\section{ABSTRACT}

\section{Background}

At the 2011 Annual Business Meeting of the Canadian Geriatrics Society (CGS), an ad hoc Work Group was struck to submit a report providing an estimate of the number of physicians and full-time equivalents (FTEs) currently working in the field of geriatrics, an estimate of the number required (if possible), and a clearer understanding of what has to be done to move physician resource planning in geriatrics forward in Canada.

\section{Methods}

It was decided to focus on specialist physicians in geriatrics (defined as those who have completed advanced clinical training or have equivalent work experience in geriatrics and who limit a significant portion of their work-related activities to the duties of a consultant).

\section{Results}

In 2012, there are 230-242 certified specialists in geriatric medicine and approximately 326.15 FTE functional specialists in geriatrics. While this is less than the number required, no precise estimate of present and future need

\footnotetext{
*The opinions expressed in this report are those of the authors and are not meant to represent the opinions or official positions of any organization.
}

could be provided, as no attempts at a national physician resource plan in geriatrics based on utilization and demand forecasting, needs-based planning, and/or benchmarking have taken place.

\section{Conclusions}

This would be an opportune time for the CGS to become more involved in physician resource planning. In addition to this being critical for the future health of our field of practice, there is increasing interest in aligning specialty training with societal needs $(\mathrm{n}=216)$.

Key words: physician resource planning, geriatrics, health services for the aged

\section{INTRODUCTION}

At the 2011 Annual Business Meeting of the Canadian Geriatrics Society (CGS), an ad hoc Work Group (WG) was struck and asked to submit a report at the time of the 2012 Annual Meeting of the CGS on physician resource needs in geriatrics. Drs. Michael Borrie and David Hogan were appointed as Co-chairs. A voluntary lead for each province and territory was to be found who would be primarily responsible for their provincial/territorial data. As no funding or resources were allocated to this exercise, the WG was to use available data, wherever possible. The goal was not to create a definitive physician resource plan, but to provide an estimate of the number of physicians and full-time equivalents (FTEs) currently working in the field of geriatrics, an estimate of the 
number required (if possible), and a clearer understanding of what has to be done to move physician resource planning in geriatrics forward.

This was not a new suggestion. In the 1993 CGS document "Blueprint for Discovery", ${ }^{(1)}$ it was recommended that a "scientifically based" Canadian physician resource plan for geriatrics be created. This suggestion was repeated in $2001^{(2)}$ and 2006. ${ }^{(3)}$ No prior response to these three calls had been made.

There are a number of limitations to this report. We do not address physician resource needs for consultants in geriatric psychiatry, medical directors in long-term care, physicians working in geriatric programs who do not provide consulting services (e.g., attending physician on in-patient geriatric unit), or primary medical care of older persons. Most older persons are (and will be) looked after by physicians without advanced clinical training in geriatrics. As such, all Canadian physicians, except for those restricting their practice to fields where they will not encounter older individuals, must master the basic knowledge, skills, and attitudes required to provide effective care to older patients. This report deals with specialist physicians in geriatrics. Part of their responsibilities is to provide the instruction required to meet the educational needs of physicians without advanced clinical training in geriatrics.

\section{METHODS}

Relevant publications known to the authors were reviewed in the creation of this report (see reference list).

Volunteer leads were identified for all Provinces and Territories (see list of authors; while in the main selfexplanatory, Dr. Jarrett led the effort for New Brunswick while Dr. Peters dealt with all three Territories). Teleconferences of the WG were held in the fall of 2011 to obtain input from members about the project and to seek agreement on core issues (e.g., scope of project, definition of specialist physicians in geriatrics), work plan, and timeline. It was agreed that we would focus on the need for specialist physicians in geriatrics. There was consensus that we would define specialist physicians in geriatrics as those who have completed advanced clinical training (or have equivalent work experience) in geriatrics and who limit a significant portion of their work-related activities to the duties of a consultant (defined as an individual to whom one refers for expert advice or services) in geriatrics.

A preliminary list of specialist physicians in geriatrics (by name and location) was created by Ms. Sarah WoolmoreGoodwin and Dr. Michael Borrie using data derived from the 2011 print edition of the Canadian Medical Directory (Scott's Directories), the Canadian Medical Directory Online (Scott's Directories), the Royal College of Physicians and Surgeons of Canada (RCPSC) website, and the College Of Physicians and Surgeons of Ontario database. Provincial and Territorial leads were asked to:
1. Verify that those listed for their province or territories (if any) were working as specialist physicians in geriatrics using the agreed upon definition;

2. If known, indicate whether they were internists with RCPSC-accredited training in geriatric medicine, family physicians with College of Family Physicians of Canada (CFPC)-accredited care of the elderly training, or had a different educational background (termed "other");

3. If known, note whether they were working part-time (which included those not working full-time and fulltime workers who spent a substantial portion of their time in non-geriatric activities) or full-time in geriatrics (accepted work-related activities included administration and academic ones, as well as clinical work); for those working part-time, the leads were asked to provide a FTE estimate of the time spent in geriatrics; and,

4. Identify physicians in their Province or Territory not listed who met the definition for specialist physicians in geriatrics (the leads were asked to provide the additional information noted above on them, if known).

Based on the above, a final list of specialist physicians in geriatrics (by name and contact information with year of graduation [in order to estimate pending retirements], type of training, and FTE, if known) was created.

The leads were asked if there was a physician resource plan in their jurisdiction dealing with specialist physicians in geriatrics. If permissible, they were asked to share this information with the WG. A final teleconference was held in March of 2012 to discuss the initial results and their implications. A preliminary report was written by one of the Co-chairs (DH) and distributed to WG members for review. Modifications to the document were made until agreement was obtained from WG members on the format and content of the report. Dissenting opinions to the recommendations made were permitted.

\section{RESULTS \& DISCUSSION}

\section{Number of Certified Specialists in Geriatric Medicine}

Those identified in standard Canadian references on the number of physicians in a specialty are nearly always certified specialists (i.e., physicians who have received certification from either the RCPSC or the Collège des médecins du Québec). We collated and summarized data on certified specialists in geriatric medicine from a number of standard sources (see Table 1). There is a good deal of provincial and territorial variability. Excluding the three Territories and using the maximum number of specialists reported, the ratio of certified specialists per 10,000 persons $65+$ ranged more than ten-fold, from 0.07 (in Saskatchewan) to 0.73 (Nova Scotia). The national ratio was 0.50 per 10,000 persons $65+$.

While the number of certified specialists is useful information, there are limitations to this metric in assessing physician resources. A count of functional specialists is more 
TABLE 1.

Certified specialists in geriatric medicine

\begin{tabular}{|c|c|c|c|c|c|c|}
\hline Prov/Terr & $\begin{array}{c}\text { Approx. } \\
\text { Population } 65+^{a}\end{array}$ & $\begin{array}{c}\text { RCPSC } \\
\text { Directory }^{b}\end{array}$ & $\begin{array}{c}\text { CMA Physician } \\
\text { Report }^{c}\end{array}$ & $\begin{array}{c}\text { Canadian } \\
\text { Medical Directory }\end{array}$ & $\mathrm{CIHI}^{e}$ & $\begin{array}{c}\text { Ratio of Certified } \\
\text { Specialists per } 10,000 \\
\text { individuals } 65+\end{array}$ \\
\hline $\mathrm{BC}$ & 675,000 & 42 & 43 & 39 & 40 & $0.58-0.64$ \\
\hline Prairies & 724,500 & 19 & 21 & 23 & 25 & $0.26-0.35$ \\
\hline Alberta & 399,300 & 13 & 15 & 15 & 17 & $0.33-0.43$ \\
\hline SK & 153,500 & 1 & 1 & 1 & 1 & 0.07 \\
\hline Manitoba & 171,700 & 5 & 5 & 7 & 7 & $0.29-0.41$ \\
\hline Ontario & $1,836,300$ & 98 & 95 & 90 & 87 & $0.47-0.53$ \\
\hline Québec & $1,209,900$ & 52 & 61 & 65 & 69 & $0.43-0.57$ \\
\hline Atlantic & 371,300 & 19 & 19 & 18 & 21 & $0.48-0.57$ \\
\hline NB & 119,600 & 7 & 7 & 7 & 9 & $0.59-0.75$ \\
\hline PE & 22,200 & 0 & 0 & 0 & 1 & $0-0.45$ \\
\hline NS & 151,500 & 11 & 11 & 10 & 10 & $0.66-0.73$ \\
\hline NL & 78,000 & 1 & 1 & 1 & 1 & 0.13 \\
\hline Territories (NT, NU, YT) & 7,800 & 0 & 0 & 0 & 0 & 0 \\
\hline Canada & $4,823,000$ & 230 & 239 & 235 & 242 & $0.48-0.50$ \\
\hline
\end{tabular}

a Approximate population 65 years of age and over (65+). Source: 2010 - Statistics Canada (accessed 28/11/2011 - http://www.statcan.gc.ca/ pub/91-520-x/2010001/tablesectlist-listetableauxsect-eng.htm).

b Number of specialists in geriatric medicine who are Fellows of the RCPSC (data base accessed 28/11/2011 - http://rcpsc.medical.org/dof/ index_e.php).

c Based on information contained in the Canadian Medical Association Masterfile, which includes all physicians (both CMA members and non-members) with a valid Canadian address. It is updated regularly with data provided by provincial/territorial medical associations, provincial registrars, medical schools, and individual physicians. The counts exclude physicians in postgraduate training and those over the age of 80 (data base accessed 22/02/2012 - http://www.cma.ca/index.php?ci_id=16959\&la_id=1).

d Source: 2011 Print Edition of the Canadian Medical Directory.

e Source: Canadian Institute for Health Information: Supply, Distribution and Migration of Canadian Physicians, 2010.

appropriate, as the scope of physician practice is not strictly dictated by their certification. Functional specialty captures the actual professional activities performed by individual physicians. Not all certified specialists are active in their area of certification, while family practitioners and other physicians (often with additional training) may be providing care in fields such as geriatrics. The count of functional specialists can be either greater or less than the number of certified specialists, depending on the balance between non-certified physicians providing specialty care and certified specialists not providing care in their field of certification.

Another issue is this is a head count and does not adjust for variations in the pattern or intensity of medical practice among individual physicians. Some of those counted may be semi-retired, working part-time, and/or providing a mix of medical services. Measuring physician resources by estimating FTEs is an attempt to standardize physician activity to a common denominator based on output or productivity. The FTE result for an individual physician quantifies their practice activity relative to what is considered a "full load". Three general approaches have been used in Canada to calculate physician FTEs. In one, physician output/productivity is based on fee-for-service billings. The second uses multiple methodologies to measure the activities of physicians remunerated under alternative payment schemes. The last approach looks at hours of work per week.

With the already significant and growing number of physicians in geriatrics being paid at least partially through alternative payment plans, methodologies for determining FTEs in this field will have to be flexible enough to collect data on all relevant activities being provided regardless of the mode of payment. Ideally, measures of productivity should include an assessment of the quality of service provided and patient outcome data.

\section{Current Number and FTEs of Functional Specialists in Geriatrics}

With the information provided by WG members, estimates for the number and FTEs of functional specialists in geriatrics were determined (see Table 2). As noted previously, in calculating FTEs administrative, academic (teaching and research), and clinical activities were included. It is emphasized that the values presented (especially for FTEs) are imprecise. The reasons for this include the general definition used for specialist physicians in geriatrics (meaning judgment had to be exercised in deciding who to include), the lack of a clear description of a FTE in geriatrics, the need 
TABLE 2.

Functional specialists in geriatrics ${ }^{\mathrm{a}}$

\begin{tabular}{|c|c|c|c|c|c|c|c|c|}
\hline \multirow[b]{2}{*}{ Prov/Terr. } & \multicolumn{2}{|c|}{${ }_{R C P S C}$ Training $^{b}$} & \multicolumn{2}{|c|}{ CFPC Training ${ }^{c}$} & \multicolumn{2}{|c|}{ Otherd } & \multicolumn{2}{|c|}{ Total } \\
\hline & No. & $F T E^{e}$ & No. & $F T E^{e}$ & No. & $F T E^{e}$ & No. & $F T E^{e}$ \\
\hline $\mathrm{BC}$ & 37 & 22.0 & 4 & 3.0 & - & - & 41 & 25.0 \\
\hline Prairies & 23 & 20.6 & 28 & 17.4 & 9 & 7.3 & 60 & 45.3 \\
\hline $\mathrm{AB}$ & 15 & 13.1 & 23 & 12.4 & 5 & 3.8 & 43 & 29.3 \\
\hline SK & 1 & 1.0 & 2 & 2.0 & 2 & 1.5 & 5 & 4.5 \\
\hline MB & 6 & 5.5 & 3 & 3.0 & 3 & 3.0 & 12 & 11.5 \\
\hline Ontario & 100 & $85.8^{\mathrm{f}}$ & 34 & $24.3^{\mathrm{f}}$ & 16 & 12.2 & 150 & 122.3 \\
\hline Québec & 63 & 61.0 & 24 & 23.5 & 2 & 3.0 & 89 & 87.5 \\
\hline Atlantic & 19 & 18.9 & 37 & 21.35 & 7 & 5.5 & 63 & 45.75 \\
\hline NB & 7 & 6.9 & 9 & 7.6 & 4 & 3.5 & 20 & 18.0 \\
\hline $\mathrm{PE}$ & - & - & 2 & 1.5 & - & - & 2 & 1.5 \\
\hline NS & 11 & 10.5 & 19 & 8.75 & 1 & 1.0 & 31 & 20.25 \\
\hline NL & 1 & 1.0 & 7 & 3.5 & 2 & 1.0 & 10 & 5.5 \\
\hline Territories (NT, NU, YT) & - & - & 1 & 0.3 & - & - & 1 & 0.3 \\
\hline Canada & 242 & 208.3 & 128 & 89.85 & 34 & 28.0 & 404 & 326.15 \\
\hline
\end{tabular}

a Does not include physicians working in geriatric programs who do not work as consultants or physicians solely providing primary care to older individuals.

b Internists with RCPSC-accredited training in geriatric medicine.

c Family physicians with CFPC-accredited training in care of the elderly.

d Includes those with other forms of training (e.g., international medical graduates with training in their country of origin), no formal training, or where their training is unknown.

e For all territories and provinces other than Ontario, the following methodology was used in calculating FTEs. A full-time practitioner was assigned an FTE of 1.0. If a specific FTE for a part-time practitioner was known that value was used. If a specific FTE for a part-time practitioner was not supplied, they were assigned a value of 0.5 . If it was unknown whether the physician was full-time or part-time, they were assigned a value of 0.5 .

$\mathrm{f}$ For Ontario, data on FTEs were available on $40.7 \%$ of the enumerated RCPSC and CFPC specialists in geriatrics with accredited training. This information was extrapolated to obtain a value for each of these groups.

to rely on the personal knowledge of Provincial/Territorial leads about local physician resources and/or their collection of primary data, difficulties obtaining confirmatory information, and limited resources and time. More precise data would require clearer definitions for both a specialist and an FTE, consistently adhering to these definitions in determining FTEs, and systematically obtaining primary information. The latter would require a substantial investment on the part of the CGS and/or others. Notwithstanding this, we feel the data presented represents an important advance in understanding current physician resources.

While the total number of physicians providing consultative services in geriatrics $(n=404)$ is substantially higher than the number of certified specialists $(n=230-242)$, it is reassuring that the number of internists with RCPSCaccredited training in geriatric medicine in Table 2 is congruent with the totals noted in Table 1. The workforce consists of a mix of certified/non-certified and part-time/ full-time specialists. Even if desired, it would not be possible within the foreseeable future to produce a sufficient number of certified specialists to deal with current and anticipated demand. Other than inadequate supply and personal choice about where to work and live, factors that limit a wider and more even distribution of certified specialists include insufficient population of older persons and/or inadequate resources for a specialty practice in geriatrics within given areas, the health needs of the local population (which will influence the priority given to geriatrics in comparison to other medical fields when recruiting physicians), and financial constraints (e.g., funding for required infrastructure, availability of billing numbers and/or salary support for physicians). Data on the reasons why physicians with accredited training chose to work part-time in geriatrics were not collected but could include income (i.e., spending time in a more remunerative field to bolster income), opportunities for more contact with medical students and postgraduate trainees (e.g., doing rotations as staff physician on medical teaching units), employment requirements (e.g., contractual obligation to provide general medical services), and/or personal interest.

We examined emergency and palliative medicine, which are areas of specialty practice in Canada facing similar challenges in merging the activities of physicians with different educational backgrounds within the workplace, to learn from their approaches. There are two routes for training in emergency medicine in Canada - a five-year residency program 
accredited by the RCPSC, and a one-year training program after a two-year family medicine residency through the CFPC. Both have a certifying examination at the completion of training. Most full-time emergency department (ED) physicians in our country are now certified through one of these two routes. CFPC-certified ED physicians outnumber RCPSC ones by a ratio of about three to one and work primarily as clinicians. In the 2012 Family Medicine emergency medicine match, a total of 128 training positions were filled. The majority of family physicians with an emergency medicine certification work primarily in EDs. ${ }^{(4)}$ RCPSC-certified physicians tend to congregate in academic centres and are more likely to do non-clinical work (e.g., administration, teaching, research, disaster planning, advising on pre-hospital care, and toxicology). ${ }^{(5,6)}$ Based on the Canadian Medical Association (CMA) Masterfile on physicians, as of 2012 there were 667 certified specialists in emergency medicine. In 2010-11, there were a total of 294 residents enrolled in RCPSC-accredited emergency medicine training programs (approximately 59 per year). The two training options are felt to complement each other. At a time when there are shortages in physicians with training in emergency medicine, a leader of the field wrote that it "does not make sense" to restrict clinical positions to RCPSC-accredited graduates. ${ }^{(5)}$

Palliative medicine training is currently a conjoint oneyear program of added competence. The CFPC treats it as an enhanced skills program and offers no certifying examination. The RCPSC accredits palliative medicine training programs, but also does not offer a certifying examination (the RCPSC is phasing out this type of training program). Graduates receive an attestation of completion of training from their respective Colleges. Between 1999 and 2010, 75 trainees were attested by the CFPC and 21 by the RCPSC. In 2010-11, there were 34 residents enrolled in a palliative medicine training program. In the future, it is proposed that a two-year subspecialty training program will be offered through the RCPSC, while a one-year program leading to a special designation in palliative medicine will be available under the aegis of the CFPC. The conjoint program will continue until these training options are in place. It appears that the field is moving towards a model similar to emergency medicine where CFPC-accredited training will prepare physicians for clinical work, while those trained through a RCPSC program will presumably focus more on administration and academic pursuits. Time will tell if this is what occurs. In 2011 there were 311 members of the Canadian Society of Palliative Care Physicians. ${ }^{(7)}$ Within the CFPC there continues to be an energetic debate about whether palliative care should be a specialty or considered a core component of family medicine. ${ }^{(8,9)}$

\section{Physician Resource Planning}

In order to address the number of specialist physicians in geriatrics needed now and in the near future, we collected information on physician resource plans for specialist physicians in geriatrics created by provinces, territories, and/or health regions. As will be seen, most jurisdictions have not developed comprehensive physician resource plans for geriatrics.

There are no physician resource plans for geriatrics in any of the three territories or the provinces of British Columbia (though most, but not all, health authorities have physician resource plans, with some actively recruiting), Alberta (local physician resource plans have been created for the alternate relationship plans of the Departments of Medicine in Calgary and Edmonton), Saskatchewan, Manitoba (the section of geriatric medicine at the University of Manitoba believes that 10 FTEs in geriatrics are required), or Québec.

In Ontario, there is no formal provincial resource plan for geriatrics. The five Regional Geriatric Programs and affiliated Specialized Geriatric Services (SGS) have initiated a mapping process for each of the Local Integrated Health Networks (LHINs) that compares the number of known practicing internist geriatricians, CFPC care of the elderly trained physicians, and other family physicians working in SGS by LHIN with the estimated required number for the LHIN calculated using a ratio of 1.25 geriatricians per 10,000 people over the age of $65 .^{(10)}$ The surplus or deficit for the LHIN is then determined. The Ministry of Health and Long-Term Care and Ontario Medical Association's 2008-2012 agreement endorsed up to 10 new geriatrician positions. A larger number of new positions are being requested in current negotiations.

There is a provincial resource plan in New Brunswick for the total number of physicians, but no target exists for geriatricians. Vacant and new positions for physicians are assigned to the eight health zones of that Province. Within zones there are discussions about which specialties should be recruited to fill vacancies. Until now, it was been possible to successfully argue for one of these vacancies when there was a "firm" (person on the ground) recruit in geriatrics. The environment is changing, and it is getting more difficult to recruit. In P.E.I., the provincial ministry of health has identified a need for three specialists in geriatrics. The Nova Scotia Department of Health and Welfare has an overall physician resource plan. The Dalhousie Division of Geriatric Medicine, with input from the health districts in Nova Scotia, has developed a provincial workforce plan for geriatrics. In Newfoundland and Labrador, physician resources are planned using a physician/population ratio model (e.g., so many per current population). There is a recognized need for three RCPSC certified specialists in geriatric medicine, but currently there is no target for the number of care of the elderly physicians required.

A commonly used approach in assessing current and future physician resource need are physician/population ratios. In 1988-89, it was estimated that 131 specialists in geriatrics were needed for the province of Ontario. ${ }^{(10)}$ Though not stated, it was implied that all these physicians would be working full-time in geriatrics (i.e., would be 1.0 FTE). 
Ninety-five were for clinical service, 29 to meet academic need, and seven for administration. A Delphi consensus survey methodology was used to come up with these numbers. A questionnaire was sent to 19 persons considered experts in health human resource planning, requesting their views on the roles of specialist physicians in geriatric medicine. Attached to the questionnaire was a map of the then five provincial health regions (with populations). Participants were asked to provide estimates for the number of specialists in geriatric medicine required for clinical service, academic roles, and administration in these regions. Fourteen of the 19 responded. Their estimates were tabulated and returned to responders asking them to either accept or revise the estimates. Eleven provided further input (recipients were told that non-return would indicate agreement). After incorporating this feedback, penultimate estimates were sent again to the 14 asking for final input. One of the 14 declined to approve the final estimates, feeling they were too high. This study is the source for the oft-quoted ratio of 1.25 specialists in geriatrics per 10,000 individuals $65+$ (or 3.3 per 10,000 individuals $75+$ ). The current ratio in Canada is between 0.48 (based on number of certified specialists) and 0.84 (based on number of functional specialists) per 10,000 persons $65+$. Using this approach, it was estimated that there was a need for 538 specialists in geriatric medicine in 2006. ${ }^{(2)}$ This number was referred to by the National Advisory Council of Aging ${ }^{(11)}$ and the Special Senate Committee on Aging. ${ }^{(12)}$ Relying on a ratio for work force planning is imprecise as it doesn't accurately reflect actual need, adjust for variations in the intensity of medical practice, or acknowledge the role of other providers. This particular ratio is based on the opinion of a small group from one province obtained nearly a quarter of a century ago. As a minimum, it should be re-examined.

Imported ratios from other countries are suspect as they don't account for international differences in factors such as population structure and expectations, practitioner occupational niche(s), structure and function of the healthcare system, and/or availability of health-care resources. In the United Kingdom (UK), the Royal College of Physicians (RCP) recommends six FTE trained specialists in geriatric medicine per 250,000 (total population) or approximately one per 40,000 persons. ${ }^{(13)}$ The British Geriatrics Society accepts this figure and also suggests there be one FTE per 4,000 persons over 75. ${ }^{(14)}$ Aside from other differences between Canada and the UK, the roles of geriatric specialists in the two countries are not identical. Compared to Canadian practitioners, UK geriatricians are more heavily committed to acute, general, and stroke medicine but less to dementia care. In 2010 there were 980 consultants in geriatric medicine (941 FTEs) employed by the National Health Service in England. The estimated need based on the RCP ratio was for 1,262 FTEs. ${ }^{(13)}$

There are now four general approaches used to model and forecast physician supply and demand: supply forecasting, utilization or demand forecasting, needs-based planning, and benchmarking. ${ }^{(15)}$ Supply forecasting looks at the number of physicians (of a particular type) anticipated to enter the work force (see "Future Influences on Physician Supply" below). Utilization or demand forecasting considers measures of physician service delivery capacity. Needs-based planning considers population health needs and approaches to care. As models become more complex, they are increasingly affected by data limitations, and become more dependent on judgment and assumptions of stability. Benchmarking avoids assumptions of stability in the health-care system. It identifies areas where delivery is perceived to be optimal and uses them as the standard.

Rigorous utilization and demand forecasting, needsbased planning, and/or benchmarking have not been used to develop a national physician resource plan in geriatrics in our country. Geriatrics would present unique challenges. For one thing, there are no conditions, procedures or age ranges that fall solely within the domain of specialists in geriatrics. As noted, the majority of older persons are (and will be) looked after by physicians without advanced clinical training in geriatrics. Older patients who are felt to require the input of geriatric specialists (or specialized geriatric services) are those with complex issues, cognitive impairment, disability, and/or frailty. ${ }^{(16)}$ More precisely defining who they are, when they should be referred, where they should be seen, and for what type of service (and for how long) has not, by and large, taken place. Requests for assistance in the assessment and management of dementia, the most common condition treated by Canadian geriatricians, ${ }^{(17)}$ could be directed to neurologists and geriatric psychiatrists/ psychiatrists, as well as geriatricians, while improving the abilities of primary care physicians to deal with this clinical condition would partially obviate the need for referrals in the first place. Compared to many other fields, though, there is an extensive body of research showing the benefits of care provided by geriatric specialists and the programs they work in. ${ }^{(18,19)}$ This can be used to provide a clearer picture of the desired role (and size) for the specialty. Another issue is that consultants in geriatrics work differently than other medical specialists. They are more likely to be part of an interdisciplinary team and have lower patient volumes (the reported mean number of estimated patient visits during a typical week for a specialist in geriatric medicine was 38.81 in the 2004 National Physician Survey compared to 67.29 for general internists), presumably because of the nature of patients seen and the type of care provided. The closest we ever came to a national physician resource plan in geriatrics was a 1988 estimate based on a survey of national leaders that we would require $550-700$ specialists in geriatric medicine by $2000 .^{(20)}$

An interesting but now older study estimated American physician resource needs in geriatrics. ${ }^{(21)}$ Based on medical service utilization, physician clinical workloads in the mid-1980s, and perceived need for geriatricians, it looked at requirements for both primary and consultant care within 
TABLE 3.

Ten-year historical trend in number of trainees ${ }^{\mathrm{a}, \mathrm{b}}$

\begin{tabular}{lccc}
\hline & Care of the Elderly & Geriatric Medicine & Total \\
\hline $2001-02$ & 14 & 23 & 37 \\
$2002-03$ & 16 & 24 & 40 \\
$2003-04$ & 13 & 15 & 28 \\
$2004-05$ & 10 & 15 & 25 \\
$2005-06$ & 12 & 15 & 27 \\
$2006-07$ & 10 & 19 & 29 \\
$2007-08$ & 14 & 24 & 38 \\
$2008-09$ & 13 & 25 & 38 \\
$2009-10$ & 9 & 23 & 32 \\
$2010-11$ & 11 & 19 & 30 \\
\hline
\end{tabular}

a Hogan DB. Geriatrics in North America. In: Fillit HM, Rockwood K, Woodhouse K, editors. Brocklehurst's Textbook of Geriatric Medicine, $7^{\text {th }}$ edition. Philadelphia, PA: Saunders Elsevier; 2010.

b Canadian Post-M.D. Education Registry (CAPER). CAPER annual census of post-m.d. trainees - 2010-11 report. Accessed November 28, 2011. Available from: http://www.caper.ca/census book_2011/toc_en.php.

three different scenarios reflecting different economic assumptions. The $2000 \mathrm{FTE}$ estimate for consultant care ranged from 1,577 to 4,176. By 2030 the projected required FTE number for primary and consultant care combined ranged from 3,153 to 12,057 . In the United States, geriatrics is now viewed as predominantly a primary medical care field. Recent estimates for the number of FTEs in geriatrics required by 2030 have risen substantially, to between 26,000 and 36,000. (22-24) These are based on assumptions about the proportion of older persons who should be cared for by geriatricians (i.e., $25-30 \%$ ) and the number of older patients a geriatrician can effectively deal with. The wide range gives a sense of the difficulty in coming up with accurate figures and how sensitive estimates are to underlying assumptions. In 2010 there were 7,029 certified geriatricians in the United States. ${ }^{(24)}$

\section{Future Influences on Physician Supply}

Several trends need to be acknowledged when looking at future physician supply. The number of active physicians in Canada is increasing at a faster rate than population growth. Over time, the average age of the physician work force has risen (it is now 50), as has the proportion of females (from $12.4 \%$ in 1980 to $36.1 \%$ in 2010$)$. ${ }^{(25)}$ One hundred and twentynine of the 237 (54.4\%) certified Canadian specialists in geriatrics where gender was known and 18 of the $30(60 \%)$ current postgraduate trainees in geriatrics are female. Rural and remote areas have particular challenges in accessing specialty services. ${ }^{(26)}$ Compared to older practitioners, younger physicians want to work fewer (and more predictable) hours within group rather than solo practices. ${ }^{(26)}$ There is a trend among family physicians toward specialization and restriction within their practice. ${ }^{(26)}$ This is particularly common among those who take a third year of training. ${ }^{(27)}$ Family medicine residents and CFPC program directors feel that approximately one-third of core family medicine program graduates should have the opportunity of a third year of training. ${ }^{(28)}$

Changes in educational policy (e.g., eligibility requirements, standards of accreditation, certifying examination) by the CFPC and/or RCPSC could have significant impacts on future supply. It is assumed that those reading this report are knowledgeable about RCPSC-accredited training in geriatric medicine and CFPC-accredited training in care of the elderly. We are unaware of any current proposal for substantive change to either training program. In the past, alternate approaches to postgraduate training were considered, though nothing came of them. In 1976, the RCPSC Committee on Specialty Development and Manpower suggested that entry for training in geriatric medicine be open to those with prior certification in specialties other than internal medicine. ${ }^{(29)}$ Ten years later, the CMA Committee on the Health Care of the Elderly recommended that geriatric medicine become a primary specialty and that a mechanism for recognizing prior CFPC training as partial requirement for certification be worked out. ${ }^{(30)}$ The RCPSC has embraced additional pathways or streams for specialty education. Areas of Focused Competence (or diploma) category will allow the RCPSC to recognize highly focused areas of specialty medicine, while Special Interest Groups of Medical Activity will serve as forums for individuals with common areas of interest. Neither designation is to adversely impact existing disciplines, but it is unclear at this time what, if any, effect this will have on RCPSC-accredited training in geriatric medicine. The potential impact of sub-specialization within geriatrics (e.g., dementia care) on physician resources was not considered by the WG.

Supply-side approaches to deal with the perceived inadequate number of specialist physicians in geriatrics are described in the following sections.

\section{More Postgraduate Trainees}

The total number of residents enrolled in a program of advanced clinical training in geriatrics over the last ten years has been limited. While the numbers vary from year-to-year, there is no clear evidence of growth (see Table 3). In 2010-11 there were 30 (11 care of the elderly trainees and 19 enrolled in geriatric medicine). Training locations (which indicate where they are more likely to practice upon completion of their training) for the 2010-11 cohort of residents are: 16 in Ontario (12 Toronto, 1 McMaster, 3 UWO); 5 British Columbia; 4 Québec (2 Laval, 2 McGill); 3 Prairies (1 Manitoba, 2 University of Alberta); and 2 in Atlantic Canada. ${ }^{(31)}$ The estimated entering practice cohort of physicians with additional training in geriatrics in 2011 was 17 (total of nine R3 care of the elderly and eight R5 geriatric medicine trainees). Over the last five years, the entering practice cohort has 
ranged from 17 to $26,{ }^{(31)}$ which is too small to substantially change access to consultants in geriatrics, especially when one considers pending retirements, challenges in retention, and the rapidly increasing number of older Canadians that will be seen over the next 30 years.

The primary problem is not having a sufficient total number of positions for qualified residents applying for training in geriatric medicine, as more than half of all available training positions have been unfilled recently. In the 2012 CaRMS R4 Medicine Subspecialty Match, less than half $(42.3 \%, 11 / 26)$ of residency positions offered were filled. ${ }^{(32)}$ The figures for 2010 and 2011 were $40 \%$ and $46.4 \%$, respectively. These rates are lower than those seen for the larger sub-specialties of internal medicine. This is not to say that there are no concerns about the distribution of available positions, but the total number of training positions is more than adequate to meet current demand.

Postgraduate training in geriatric medicine has become concentrated in two Faculties - the University of Toronto and UBC. Over the last three years, 19 out of the 32 (59.4\%) residents who entered a training program in geriatric medicine were matched to these schools. ${ }^{(32)}$ In sub-specialty training, larger programs are generally more successful in attracting residents. One would expect this concentration to continue. As residents entering practice tend to stay close to where they received their training, this could present recruitment challenges to other regions of the country.

The situation might well change in the future. For one thing, there is reawakening interest in developing a national strategy to better align physician training to population needs. "Employment difficulties" for new graduates have been reported in seven specialties (cardiac surgery, nephrology, neurosurgery, plastic surgery, public health and preventive medicine [community medicine], otolaryngology, radiation oncology) with other fields (e.g., orthopedic surgery) expected to soon have similar challenges. ${ }^{(33)}$ Students may vote with their feet, with fewer applying for training in these fields. They could be potentially recruited into areas with better job opportunities like geriatrics. Students are asking for better career planning tools. A motion passed at the $2011 \mathrm{CMA}$ annual meeting called upon the organization to provide job-trend data and other career planning resources. Another resolution will compel the Association to promote a national alignment of training positions with "current and future societal needs, evolving models of care delivery and available health system resources."(34) More effective "marketing" of geriatrics to both medical students and postgraduate trainees might bear fruit. ${ }^{(12,35)}$

\section{More Re-entry Positions and Enhanced Professional Development Opportunities for Practicing Physicians}

More re-entry training positions for CFPC and RCPSCaccredited training would allow greater opportunities for practicing physicians to "re-tool" as specialists in geriatrics.
This would require funding and the allocation of residency positions. A number of the functional specialists listed in Table 2 were "trained on the job". Standards and educational resources need to be developed for them.

\section{Increased Immigration}

Allowing more international medical graduates with geriatric training to enter the country is a possible short-term response to our current shortfall. We would need to ensure that the training and skills they bring are congruent with our national needs, they remain in geriatrics after moving to Canada, and their recruitment doesn't disadvantage Canadian trainees. There are ethical concerns about recruiting internationallytrained health professionals from developing countries that also require consideration. ${ }^{(36)}$

\section{Greater Retention and/or Commitment to Geriatrics}

Having trained individuals leave geriatrics is a regrettable and potentially preventable loss of physician resources. Retention appears to be a particular issue for those with care of the elderly training. A survey of care of the elderly graduates indicated that over half (55.8\%) end up in a general family medicine practice. ${ }^{(37)}$ Since the development of this postgraduate training option in 1989, an estimated 160-170 physicians (the CFPC doesn't have a precise cumulative count) have completed training. Based on our determination of functional specialists, an estimated 40 of these physicians have been lost from the field. We need a better understanding of why this occurs. Equally important is examining the time spent in other clinical areas by practicing geriatricians. Among RCPSC-accredited specialists, we are losing 30-40 FTEs because of non-geriatric commitments. We need to assess the relative benefits and negative consequences of this on specialized geriatric services in our country. Time spent in other fields can be entirely appropriate. For example, specialists in geriatric medicine often attend on medical teaching units and/or work as internists in emergency rooms. In addition to providing a greater opportunity for them to instruct medical students and postgraduate trainees on the principles of geriatric care, there could be direct benefits for the many older patients they would see. Because of the unique knowledge, skill set, and approach they bring to the care of these patients, their involvement might lead to better outcomes such as lower mortality rates, better functional outcomes, less iatrogenesis, a greater proportion discharged back home, and/or lower readmission rates (these assertions could be evaluated in a pragmatic clinical trial). We have to weigh, though, the opportunity cost (i.e., the benefit that could have arisen by taking alternative action) of the time spent in non-geriatric activities and the risk of spreading ourselves too thin, which could have negative impacts on both the quality of work provided and its long-term sustainability. With our limited physician resources, we have to carefully prioritize 
the various ways we allocate our time. Concurrently we should point out to decision-makers the additional meritorious activities we could perform if we had sufficient numbers.

\section{Postponing Retirement}

According to the CMA Masterfile, 82 of the 233 (35.2\%) certified specialists in geriatrics where age is known are 55 years of age and older. While hard to precisely predict when a given physician will retire, many practicing specialist physicians are closer to the end of their careers than to the beginning. If one assumes that physicians retire 40 years after receiving their MD degree, we can estimate the expected number of retirements over the coming years. We should not focus solely on the complete cessation of work as prior to this, many physicians will reduce their workload and/or narrow their scope of practice, which has implications for physician work force planning. Strategies to keep older physicians engaged would include creating more job opportunities in non-clinical areas and flexibility in structuring part-time work.

\section{Making Geriatrics More Attractive}

This is critical in all supply-side attempts to deal with a deficient number of practitioners. While efforts to improve physician recruitment and retention have historically focused on financial incentives, other ones should be considered. The overlapping factors that influence career decisions can be categorized as educational (e.g., early and on-going exposure to the field, length and availability of training opportunities, exposure to role models/mentors), professional (e.g., availability of positions, scope and type of practice, workload, frequency and intensity of on call responsibilities, professional support and collegiality, administrative support and availability of infrastructure, opportunities for professional development), personal or lifestyle (e.g., pre-existing interests and life experiences, desire for work-life balance, opportunities for part-time work/job sharing, family-friendly work environment, quality of life), and financial (e.g., level and stability of income, reimbursement for overhead expenses, availability of bursaries, debt relief/assistance, student loan forgiveness). A recent report by the Institute for Clinical Evaluative Sciences showed that mean and median payments to geriatricians remained significantly below the average for all physicians in Ontario. ${ }^{(38)}$ (Note: At the time this report was written, similar data were not available for other provinces.) Poor remuneration has long been perceived by many geriatricians as a major barrier to recruitment. (16) While physicians should not be bribed to work in geriatrics, remuneration should not be a disincentive to considering the field. To make serious inroads on these issues will require a long-term commitment on the part of practitioners, medical and health leaders, and the CGS.

\section{Influences on Productivity}

Our ultimate goal is to improve the accessibility, effectiveness, and efficiency of specialized geriatric services. The first goal in particular might benefit from the innovative use of technology (e.g., telehealth, decision-support information technology) and labour substitution (e.g., expanding scopes of practice for other health professionals). Specialist physicians in geriatrics require infrastructure (e.g., interdisciplinary teams) to be fully effective. It is important to ensure that these teams are funded and available to them. Over time, new approaches and alternative models of care for older patients will be developed. As a specialty we should support their creation, critical evaluation, and dissemination, if found to be worthwhile. The implications of factors influencing productivity have to be considered in physician resource planning.

\section{CONCLUSION \& RECOMMENDATIONS}

The determination of current physician resources turned out to be a complex exercise. We view this report as just a start with further work required, especially as we move into areas such as assessing need and projecting requirements into the future. As noted, the values presented (especially for FTEs) are imprecise because of the general definition we used for specialist physicians in geriatrics, the lack of a clear description of a FTE in geriatrics, the need to rely on the personal knowledge of Provincial/Territorial leads about local physician resources and/or the collection of primary data, difficulties obtaining confirmatory information, and limited resources and time. More precise data would require clearer definitions for both a specialist and an FTE, consistently adhering to these definitions in determining FTEs, and systematically obtaining primary information.

This would be an opportune time for the CGS to become more involved in physician resource planning. In addition to this being critical for the future health of this field of practice, there is increasing interest in aligning specialty training with societal needs. ${ }^{(34)}$ Health human resource planning aims at having the right number and type of practitioners available to provide the right services to the right people at the right time. In an efficient system, there would be timely implementation of effective policies to address discrepancies between requirement and supply. ${ }^{(39)}$ Canada has lagged behind other developed countries in creating a national strategy for planning the future supply of practitioners. There have been a number of recent calls for action on this front. ${ }^{(40,41)}$ The first recommendation of "The Future of Medical Education in Canada Postgraduate Report" deals with health human resource planning: "In the context of an evolving health-care system, the PGME [Postgraduate Medical Education] system must continuously adjust its training programs to produce the right mix, distribution, and number of generalist and specialist physicians - including clinician scientists, educators, and leaders - to serve and be 
accountable to the Canadian population."(42) One issue the CGS should consider is whether specialists in geriatrics can and/or should describe themselves as generalists (for older people). The preceding report calls for more generalists which from their perspective includes general internists, general surgeons, general psychiatrists, and general pediatricians as well as family physicians.

We found that the total number of specialist physicians is greater than the current membership of the CGS. We encourage the Society to reach out to those who are not members and invite them to join. The Society will have to reassure these potential members that it speaks to and for their interests. It is important for the Society to start a dialogue with the Canadian Academy of Geriatric Psychiatry, Long-Term Care Medical Directors Association of Canada, and others on the supply side of the equation. Bridges have to be built with potential allies like the Alzheimer Society of Canada, who in their report on the future impact of the rising burden of dementia on Canadian society advocated for more geriatricians. ${ }^{(43)}$ The Society can play an important role by providing accurate information, informed advice, and perspective on physician resource issues. For example, in an otherwise sympathetic commentary about limited access to geriatricians, a report by the Canadian Institute for Health Information stated that the situation was improving because "the number of medical doctors entering geriatrics training increased by $27 \%$ between 2005 and 2010." (44) This reassuring statement was based on an absolute increase of 4 in the total number of geriatric medicine trainees (from 15 in 2005-2006 to 19 in 2010-2011). Comparing 2008-2009 to 2010-2011 could have led to the depressing conclusion that the number had decreased $24 \%$ (from 25 to 19). We feel this is an example of mistaking noise (background irrelevant data) to signal (useful information).

WG recommendations submitted to the Council of the CGS were:

1. The over-riding interest of the CGS in physician resource planning must be on ensuring that older Canadians have access to an effective, efficient, and humane health-care system. This will entail being clear on what is truly important, open-minded and flexible on non-critical issues, and willing to balance the ideal with the feasible.

2. If the CGS wishes to be a credible voice in the field of physician work force planning, it must provide a balanced, reasoned perspective and allocate funding (and other resources) to the activity. While without doubt we face challenges, being unreasonably gloomy and/or making unrealistic projections about future need will potentially drive away recruits, reinforce the belief that it is already too late, ${ }^{(45)}$ and/or contribute to the sense that geriatrics is a "luxury item". (21)

3. Future specialist physician resource planning in geriatrics should focus on determining the FTEs of functional specialists required. In 2006, the National Advisory
Council on Aging stated that we needed better data on the number of FTE specialists in geriatrics. ${ }^{(11)}$

4. While we are confident that the current FTEs of specialist physicians in geriatrics is less than the number required, at this time we can give no precise estimate of the present and future need for them. The CGS should support the determination of current and future physician resource needs using appropriate evidence-based methodologies.

5. Physician resource planning not linked to effective action will be futile. A national action plan should be multi-faceted, long-term, and modifiable as circumstances change. There are a variety of approaches to increasing the physician resource workforce. All should be explored and wherever appropriate and feasible supported by the CGS.

6. The education of physicians without advanced training in geriatrics about the appropriate care of older patients is an essential component of the response of the healthcare system to societal aging. The current status of this in our country is far from ideal. While the CFPC standards for accreditation of family medicine training programs have specific requirements dealing with education about the care of older patients, they are generally lacking in RCPSC-accredited specialty and subspecialty programs. (46) It is currently possible in Canada to complete eight or more years of undergraduate and postgraduate medical training and receive a total of 10 hours of mandatory teaching in geriatrics. ${ }^{(47)}$

7. Given their crucial role in undergraduate and postgraduate training of physicians, the CGS must engage the Association of Faculties of Medicine of Canada, CFPC, RCPSC, and Collège des Médecins du Québec in addressing the issues raised in this report.

\section{CONFLICT OF INTEREST DISCLOSURES}

The authors declare that no conflicts of interest exist.

\section{REFERENCES}

1. Canadian Society of Geriatric Medicine. Blueprint for discovery - a strategy for aging research in Canada. Vancouver, BC: Canadian Geriatrics Society; 1993. p. 37-38, 88-100.

2. Hogan DB. Human resources, training and geriatrics. Geriatric Today. 2001;4:1-4.

3. Hogan DB, Shea CL, Frank CC. Education of specialists in the care of older individuals. Can J Geriatr. 2006;9(Suppl 1):S19-S24.

4. Chan BTB. Do family physicians with emergency medicine certification actually practice family medicine? CMAJ. 2002;167(8):869-70.

5. Ducharme J. Preparing emergency physicians for the future. CMAJ. 2003;168(12):1548-49.

6. Steiner IP. Emergency medicine practice and training in Canada. CMAJ. 2003;168(12):1549-50. 
7. Information from the Canadian Society of Palliative Care Physicians. Accessed April 25, 2012. Available from: http:// www.cspcp.ca/english/aboutus.php

8. Shadd J. Should palliative care be a specialty? Yes. Can Fam Physician. 2008;54(6):840-43.

9. Vinay P. Rebuttal: Should palliative care be a specialty?No. Can Fam Physician. 2008;54(7):974.

10. Patterson C, Dalziel WB, Goldlist BJ, et al. Geriatric medicine in Ontario: manpower predictions based on a Delphi consensus survey. Ann RCPSC. 1992;25:99-102.

11. National Advisory Council on Aging. Seniors in Canada - 2006 report card. Ottawa, ON: Public Health Agency of Canada; 2006.

12. The Honourable Sharon Carstairs (Chair), The Honourable Wilbert Joseph Keon (Deputy Chair). Canada's aging population: seizing the opportunity. Special Senate Committee on Aging Final Report. Ottawa, ON: The Senate of Canada; 2009.

13. Centre for Workforce Intelligence. Geriatric medicine: CIWI medical fact sheet and summary sheet-August 2011. London, UK: Centre for Workforce Intelligence; 2011.

14. The challenge of consultant geriatric medicine in England. BGS Online Newsletter. January 2005.

15. Canadian Institute for Health Information. Supply, distribution and migration of Canadian physicians. Ottawa, ON: Canadian Institute for Health Information; 2010.

16. Hogan DB. Proceedings and recommendations of the 2007 Banff Conference on the Future of Geriatrics in Canada. Can J Geriatr. 2007;10(4):133-48.

17. Hogan DB. 2004 National Physician Survey: Geriatric Medicine Specialists. Can J Geriatr. 2006;9(Suppl 1):S27-S28.

18. Ellis G, Whitehead MA, Robinson D, et al. Comprehensive geriatric assessment for older adults admitted to hospital: metaanalysis of randomised controlled trials. BMJ. 2011;343:d6553.

19. Bachmann $\mathrm{S}$, Finger $\mathrm{C}$, Huss $A$, et al. Inpatient rehabilitation specifically designed for geriatric patients: systematic review and meta-analysis of randomised controlled trials [correction]. BMJ. 2010;340:c1718.

20. Gordon M. Patterson C, Wilson DB, et al. Geriatric medicine: a challenge for the present and future. Ann RCPSC. 1991;24:194-96.

21. Reuben DB, Zwanziger J, Bradley TB, et al. How many physicians will be needed to provide medical care for older persons? Physician manpower needs for the twenty-first century. J Am Geriatr Soc. 1993;41(4):444-53.

22. Alliance for Aging Research. Medical never-never land - ten reasons why America is not ready for the coming age boom. Washington, DC: Alliance for Aging Research; 2002.

23. Fried LP, Hall WJ. Leading on behalf of an aging society [editorial]. J Am Geriatr Soc. 2008;56(10):1791-95.

24. The American Geriatrics Society. Projected future needs for geriatricians. New York, NY: The American Geriatrics Society; 2010.

25. Canadian Labour and Business Centre. Physician workforce in Canada: literature review and gap analysis. A Physician $\mathrm{Hu}-$ man Resource Strategy for Canada Task Force Two. Ottawa, ON: Canadian Labour and Business Centre; 2003.
26. Canadian Labour and Business Centre and Canadian Policy Research Networks. Canada's physician workforce - occupational human resources data assessment and trends analysis. A Physician Human Resource Strategy for Canada Task Force Two. Ottawa, ON: Canadian Labour and Business Centre; 2005.

27. Green M, Birtwhistle R, MacDonald K, et al. Practice patterns of graduates of 2- and 3-year family medicine programs. Can Fam Physician. 2009;55(9):906-07.

28. Green M, Birtwhistle R, MacDonald K, et al. Resident and program director perspectives on third-year family medicine programs. Can Fam Physician. 2009;55(9):904-05.

29. Minutes of the Committee on Specialty Development and Manpower. Ottawa, ON: Royal College of Physicians and Surgeons; 1976.

30. Canadian Medical Association. Health care for the elderly today's challenges, tomorrow's options. Report of the CMA Committee on the Health Care of the Elderly. Ottawa, ON: Canadian Medical Association; 1987.

31. Canadian Post-M.D. Education Registry (CAPER). CAPER annual census of post-m.d. trainees - 2010-11 Report. Accessed November 28, 2011. Available from: http://www.caper. ca/census_book_2011/toc_en.php

32. Canadian Resident Matching Service. Number of matched Applicants by First Choice Discipline and Quotas by Discipline. Data for 2010, 2011, and 2012 matches. Accessed March 18, 2012. Available from: http://www.carms.ca/eng/ operations_R4reports_e.shtml

33. Rich P. Bleak job outlook in some specialties sparking concern. Ottawa, ON: Canadian Medical Association; 2011. Accessed March 18, 2012. Available from: http://www.cma.ca/bleakjob-outlook-specialties

34. Vogel L. Specialty training out-of-sync with job market. CMAJ. 2011;183(13).

35. Torrible SJ, Diachun LL, Rolfson DB, et al. Improving recruitment into geriatric medicine in Canada: findings and recommendations from the geriatric recruitment issues study. $J \mathrm{Am}$ Geriatr Soc. 2006;54(9):1453-62.

36. NcIntosh T, Torgerson R, Klassen N. The ethical recruitment of internationally educated health professionals: lessons from abroad and options for Canada. Ottawa, ON: Canadian Policy Research Networks; 2007.

37. Frank C, Seguin R. Care of the elderly training - implications for family medicine. Can Fam Physician. 2009;55(5):510-11.

38. Henry DA, Schultz SE, Glazier RH, et al. Payments to Ontario physicians from Ministry of Health and long-term care sources, 1992/93 to 2009/10. ICES Investigative Report. Toronto, ON: ICES; 2012.

39. Birch S, Kephart K, Murphy GT, et al. Health human resources planning and the production of health: development of an extended analytical framework for needs-based health human resources planning. J Public Health Management Practice. 2009;15(6 Suppl):S56-S61.

40. Belluz B. Doctor unemployment? Really? The Medical Post. 2012 January 31; p. 8-9, 12. 
41. Belluz J. Human-resource planning needed to fix 'doctor glut.' The Medical Post. 2012 February 28; p. 4.

42. The Future of Medical Education in Canada. A collective vision for postgraduate medical education in Canada. Ottawa, ON: Health Canada; 2012. p. 13.

43. Alzheimer Society. Rising tide: the impact of dementia on Canadian society. Toronto, ON: Alzheimer Society of Canada; 2010. p. 55.

44. Canadian Institute for Health Information. Health care in Canada, 2011: a focus on seniors and aging. Ottawa, ON: Canadian Institute for Health Information; 2011. p. 53.

45. Gawande A. The way we age now. The New Yorker. 2007 April 30. Accessed March 25, 2012. Available from: http:// www.newyorker.com/reporting/2007/04/30/070430fa_fact gawande
46. Hogan DB. Specialty medical education and care of older Canadians: review of specialty and subspecialty training objectives and specific training requirements. Geriatr Today. 2004; 7:128-34.

47. Gordon JE. Updated survey of the geriatrics content of Canadian undergraduate and postgraduate medical curricula. Can Geriatr J. 2011;14(2):34-39.

Correspondence to: David B. Hogan, MD, FRCPC, HSC-3330 Hospital Dr. NW, Calgary, Alberta T2N 4N1, Canada.

E-mail: dhogan@ucalgary.ca 